\title{
Expression of Regional Culture Characteristics of Soft Decoration in Rural Recreation Area Planning*
}

\author{
Lixia Wang \\ Panzhihua University \\ Panzhihua, China
}

\begin{abstract}
In the field of rural tourism with great development prospects, the characteristic regional culture is the key excavation object for building tourism brands. In the planning of recreation area, the regional cultural characteristics are mainly carried by soft decoration. This paper focuses on the development prospects of rural tourism and the planning principles of rural recreation areas. In this process, the focus of soft decoration with regional cultural characteristics is the role and function of indoor textiles.
\end{abstract}

Keywords—rural tourism; soft decoration; regional characteristics

\section{INTRODUCTION}

With the rapid development of modern tourism, the tourism consumer market is increasingly rich and diverse. As urban diseases emerge and the well-being of residents in cities decreases, rural tourism is becoming more familiar to the public. Especially since the beginning of this century, the unique farm life of "facing the farm after opening the window and drinking wine while chatting" has attracted more and more urban people. This trend has risen in the 1980s and undergone two stages in its development. First is the stage of sightseeing experience, with the main content of "eating country style food, living in farmhouses, enjoying the happiness of farmhouse, and viewing rural landscapes". The second is the leisure and holiday stage when the tourists pay more attention to the tourism products with modern leisure and entertainment elements and their requirements are getting higher and higher.

Rural tourism first developed in the eastern coastal provinces and slowly spread to all parts of China. Its rise has enriched the leisure life of urban residents, broadened the peasants' way of getting rich, also promoted the development of the holiday economy, and achieved good social benefits and economic benefits. Relatively speaking, the development of rural tourism in Zhejiang and other places is relatively mature and earlier, while that of the Sichuan area started relatively late, and rural tourism products are slightly lagging behind. A large number of rural tourism in Sichuan, especially in the west of Panxi exists in the form of agritainment. Because of the limitations in grades, tastes and services and the similar business content including three old kinds "eating, playing cards and fishing", it is entirely possible to be abandoned by consumers if it is not transformed although it was popular at that time.

The transformation and upgrading of agritainment is a problem that people who are committed to the sustainable development of tourism industry need to think about. The solution can also refer to the mature cases in the east China, mainly involving the following aspects: first, enhancing the image of indoor and outdoor landscapes, increasing the sense of design and doing a good job in design. For example, we can make full use of the unique materials of the country as the main factors, such as wood, bamboo, stone, tiles, etc., so that the waste is used as a landscape integrated to natural environment. Second, it is suggested to improve hardware quality and style, and develop matching functional facilities for consumers to increase user comfort. Different tourists have different pursuit of lifestyle, values and travel motivation when facing the rural landscape. Children like fresh things, so they have a high participation in amusement facilities, historical and cultural bases, traditional folk programs, and traditional snacks. Young people prefer to communicate and have certain self-consumption ability, so they are enthusiastic about participating in entertainment project to get the acquisition of cognitive emotions and experience, such as experiencing teahouses, purchasing cultural souvenirs, and experiencing farming culture; middleaged tourists have strong consumption ability, so they mainly take leisure tourism, such as visiting ceremonial learning, temple worship, experiencing farming culture, etc.; middleaged and old tourists have strong sense of identity to history and culture, so they choose leisure sports to relax, such as traditional ritual learning and traditional old-age group activities. Third, it is necessary to improve marketing strategies and focus on marketing. We should make full use of the Internet + , combine online and offline and carry out continuous publicity and promotion activities. It is also necessary to do a good job in the community and build a platform. We can also skillfully use packages and activities to analyze and cultivate existing weekday sources. Promotion in the tourist season cannot be ignored because of large number of tourists. It is suggested to take advantage of the thrust, expand marketing, and overflow customers.

*This article is the Project of Sichuan Landscape and Recreation Research Center: JGYQ2017025 


\section{PLANNING AND DESIGN PRINCIPLES FOR RURAL RECREATION AREAS}

The modern rural landscape design is based on the theme of tourism experience. It meets the needs of tourism experience from the natural and humanistic aspects of landscape resources, enhances the regional characteristics of the countryside, and strives to highlight the achievements of regional ecological construction from the regional, contemporary and cultural aspects. The experience is not created without foundation, but is formed by interactions between visitors and the surrounding landscape. To this end, in the planning and construction of rural landscapes, designers should focus on creating an appropriate environment to meet the needs of visitors, and properly handle the emotional interaction and communication between landscape design and tourists, to make them feel the strong regional characteristics and gain a sense of belonging and identity in appreciation, learning, recreation and experience. As a comprehensive planning project, rural landscape design should strengthen the way and type of recreation experience both theoretically and practically, combine the cultural resources of regional characteristics, and integrate ecological and humanity characteristics from the layout of visual image and space environment to create a unique aesthetic environment and atmosphere for the tourists. In the expression of regional cultural characteristics, it is necessary to combine the region and the era, and carry out landscape design and expression through the methods of preserving, reproducing, symbolizing, metaphor, and abstract in the creation of a regional rural landscape environment to reflect the alienation and characteristics of different regional rural landscape, enrich the content of recreational activities, and touch the mind and body aesthetic consciousness of the tourists.

It can be seen from the above that the planning and design of the rural landscape recreation area mainly follows the following principles: Firstly, the recreation resources are rationally allocated from the protection of ecological balance. In the allocation of various recreational space resources, it is necessary to fully explore all kinds of recreation functions from existing regional resources, natural resources and human landscape resources and give them regional characteristics. Secondly, we pay attention to the excavation of regional culture to reflect the spirit of the times. A region has its own history and culture, and protection and excavation of precious historical memories can also highlight regional characteristics from the promotion of regional humanistic care and the spirit of the times. Finally, it is necessary to pay attention to the penetration and integration of image functions in landscape design, especially to satisfying the recreational demand. The creation of recreation space is the basis for satisfying the needs of the tourists. The development of landscape resources requires a pleasant physical and mental experience from viewing, playing, rewarding and enjoying. Therefore, we should infiltrate the regional cultural characteristics from the rural landscape design, take the recreation products and the experience of the tourists as an important part throughout, and form a comprehensive complex with landscapes, facilities and services, which is convenient for the tourists to feel the culture, history, and landscape experience from the landscape construction.

\section{THE Role FunCtion OF THE FEATURED SOFT DECORATION DESIGN}

All movable elements in the commercial space environment and the living space environment are collectively referred to as soft deco, and can also be called soft outfit and soft decoration. The elements of soft decoration include furniture, decorative painting, ceramics, floral green plants, fabrics, lighting, other decorative ornaments, etc.; the scope of soft decoration include family housing and commercial spaces, such as hotels, clubs, restaurants, bars, office spaces, etc. The indoor spaces with human activities require soft furnishings. Every area and every product of the soft decoration is an integral part of the overall environment. The soft decoration of rural landscape also has and contains these elements, mainly focusing on the rural landscape. The soft decoration in the recreation area is a creative fusion of the complex environment of the overall environment, space aesthetics, furnishings art, life functions, material style, artistic conception, personality preferences, and even geomantic culture. Although currently people's enthusiasm for travel is increasing, many people will have sense of loss after returning from tour. They think that the scenic spots are not worthy of their names and the connotations are insufficient. In addition to the lack of hardware facilities and the quality of service to be improved, the reason may be that the soft decoration design of the scenic spot lacks the necessary cultural connotation so that it cannot bring a good experience to visitors.

In rural tourism, an important embodiment of soft decoration is landscape soft decoration. The landscape soft decoration design penetrates into the process of people's life and lifestyle through creative art, and it is also the finishing touch of the whole scenic spot. As an "emerging part" in the design industry in recent years, the soft decoration in rural scenic spots mainly involves the following aspects: sculpture, amusement facilities, gazebos, promenades, flower boxes, flower stands, floats, flower boats, leisure tables and chairs, mobile or fixed vending carts, booths, logo guidance systems, sanitation facilities and so on.

However, in rural tourism, and even other forms of tourism, another important manifestation of soft decoration is indoor soft decoration. In the past two years, while the rural tourism with the goal of returning to nature and relaxing body and mind has gradually received widespread attention and recognition from the market and society, the $\mathrm{B} \& \mathrm{~B}$ has been recognized and praised by more people. Many B\&B become the destination of tourism, and people's love for the $\mathrm{B} \& \mathrm{~B}$ is also rising. Today, the generation after the $80 \mathrm{~s}$ and $90 \mathrm{~s}$ has the gene of independent aesthetic and the pursuit of freedom at their core. They long for freedom and like to walk. During the trip, they hate the monotonous hotel-style service, and are keen on youth hostels, B\&B, etc. to experience the lifestyle of the locals and integrate into the living experience of local people. Especially in some tourist hotspots, such as Dali, Lijiang, "B\&B" is implementing personalized and 
differentiated operations, focusing on meeting the needs of consumers. Compared with the indoor soft decoration in ordinary home decoration, the hotel or B\&B in the scenic area should highlight the characteristics and individuality, with the distinctive identification elements of the tourism. This function is largely done by interior textiles with regional characteristics. In general, the functions of regional features and soft furnishings mainly include: increasing aesthetic taste and cultural connotation; inheriting national culture to carry forward national characteristics; creating an indoor atmosphere and improving living environment.

\section{EXPRESSION OF NATIONAL CHARACTERISTICS OF INDOOR TEXTILES}

In the rural tourism in the western region, the soft decoration with regional characteristics is mainly reflected in the textiles with strong national style. The national characteristics are integrated into the interior design of the hotel or B\&B. With its unique nationality and diversity, the national culture is inherited, the local tourist business card is highlighted, and the regional image is strengthened.

People who live in cities for a long time usually want to be close to nature. They hope to find spiritual homes from traditional culture. Only the nation is the world, which makes the interior soft decoration design face new challenges, so the application of ethnic soft clothing in interior design is necessary.

National characteristics can be reflected in many fields, and the flexibility of interior textile design can make it more fully embodied. Different decorative materials, decorative patterns and decorative techniques can reflect the characteristics of different regions and ethnic groups. It is well known that the greatest characteristic of the national style is the strong color and unique patterns, and these elements usually appear in the expression form of cloth, printing and totem. The most commonly used products in indoor soft decoration are also these types of products, such as printed fabrics, woven carpets and totems. The current indoor soft decoration design mainly makes some coordinated match of furniture, murals, flowers, textiles, lamps, etc. by purchase, but a few adopt individual design and customized way. The former is a more common form, such as picking a pillow with ethnic flavors, laying a carpet with a national wind totem, and choosing a representative color of furniture such as small benches and leisure chairs to make an embellishment. However, there is no doubt that the uniqueness of the latter can better cater to the modern people with increasingly demand. The function of fabrics is extremely powerful in interior decoration, which allows you to design tablecloths, carpets, bedding, wall coverings, curtains and other interior textiles based on specific themes, so as to create a unique sense of style and theme. The perfect combination of national characteristics and modern design allows visitors to experience the national culture in an immersive way when enjoying the ease and pleasure of design.

\section{CONCLUSION}

The expression of regional culture of soft decoration is not only a business card in rural tourism, but also has social value. The soft decoration design of ethnic characteristics can not only reflect the design style and design concept of interior decoration art, but also fully inherit and promote local excellent culture, showing national wisdom and aesthetics. Especially in today's tourism industry with high grade, the regional characteristic of soft decoration design is inevitably an indispensable perspective in the planning rural recreation areas.

\section{REFERENCES}

[1] Che Zhulin, Yu Linglian, Lu Song. Study on the Tourism Development of Jianghuai Weibao Cultural Landscape - Taking the Four Fortresses in Feixi County as an Example[J]. Yunnan geographic environment research, 2014,(04):54-59. (in Chinese)

[2] Song Xiaozhen. Taking architectural design as an example to discuss the regional and national characteristics of design $[\mathrm{J}]$. Art Science and Technology, 2014, (12): 160. (in Chinese)

[3] Wang Jiang, Zhao Jilong, Zhou Zhongkai. The Mechanism of Cooccurrence of Planning Space and Self-Service Space in the Process of Rural Settlement Community[J]. Journal of Hunan City University, 2014, (05): 33-38+2. (in Chinese) 